\title{
A Single Complementary-Sense Transcript of a Geminiviral DNA $\beta$ Satellite Is Determinant of Pathogenicity
}

\author{
Muhammad Saeed, ${ }^{1,2}$ S. A. Akbar Behjatnia, ${ }^{1}$ Shahid Mansoor, ${ }^{2}$ Yusuf Zafar, ${ }^{2}$ Shahida Hasnain, ${ }^{3}$ and \\ M. Ali Rezaian ${ }^{1}$ \\ ${ }^{1}$ Horticulture Unit, CSIRO Plant Industry, P.O. Box 350, Glen Osmond, SA 5064, Australia; ${ }^{2}$ National Institute for Biotechnology \\ and Genetic Engineering (NIBGE), P.O. Box 577, Jhang Road, Faisalabad, Pakistan; ${ }^{3}$ Department of Botany, University of \\ The Punjab, P.O. Box 54590, Quaid-e-Azam Campus, Lahore, Pakistan
}

Submitted 29 April 2004. Accepted 10 August 2004.

Small circular single-stranded DNA satellites, termed DNA $\beta$, have recently been found associated with some geminivirus infections. The DNA $\beta$ associated with Cotton leaf curl virus is responsible for symptom expression of a devastating disease in Pakistan. Mutagenesis of DNA $\beta$ revealed that the complementary-sense open reading frame (ORF) $\beta \mathrm{C1}$ is required for inducing disease symptoms in Nicotiana tabacum. An ORF present on the virion-sense strand $\beta V 1$ appeared to have no role in pathogenesis. Tobacco plants transformed with a $\beta C 1$ ORF under the control of the Cauliflower mosaic virus 35S promoter or with a dimeric DNA $\beta$ exhibited severe disease-like phenotypes, while plants transformed with a mutated version of $\beta \mathrm{C1}$ appeared normal. Northern blot analysis of RNA from the transgenic plants, using strand-specific probes, identified a single complementary-sense transcript. The transcript carries the full $\beta C 1$ ORF encoding a 118-amino acid product. It maps to the DNA $\beta$ at nucleotide position 186 to 563 and contains a polyadenylation signal $18 \mathrm{nt}$ upstream of the stop codon. A TATA box is located $43 \mathrm{nt}$ upstream of the start codon. Our results indicate that $\beta C 1$ protein is responsible for DNA $\beta$ induced disease symptoms.

Additional keywords: Begomovirus, Geminiviridae, gene expression.

Geminiviruses are characterized by their circular, singlestranded genomes encapsidated in twinned quasi-isometric particles and are responsible for major crop losses worldwide (Brown and Bird 1992; Hanley-Bowdoin et al. 1999). The majority of members of the family Geminiviridae belong to the genus Begomovirus, which is transmitted by the whitefly $\mathrm{Be}$ misia tabaci. Most begomoviruses have bipartite genomes, referred to as DNA A and DNA B. The DNA A encodes viral proteins required for DNA replication, control of gene expression, encapsidation, and insect transmission. DNA B encodes two proteins involved in viral systemic movement (Noueiry et al. 1994; Stanley and Gay 1983) and symptom expression (Klinkenberg and Stanley 1990; von Arnim and Stanley 1992). The monopartite begomoviruses contain a single DNA compo-

Corresponding author: M. A. Rezaian; E-mail: ali.rezaian@csiro.au

* The $\boldsymbol{e}$-Xtra logo stands for "electronic extra" and indicates Figures 1, 3, 4 , and 5 appear in color online. nent that resembles DNA A of bipartite begomoviruses (Dry et al. 1993; Kheyr-Pour et al. 1991; Navot et al. 1991; Noris et al. 1994). DNA A carries all gene functions for replication and pathogenesis and somehow compensates for the lack of a DNA B component.

The first viral satellite DNA was found to be associated with Tomato leaf curl virus (TLCV) from Australia (Dry et al. 1997). This 682-nt DNA depends on TLCV for its replication and encapsidation but can also be supported for replication by other geminiviruses. It has no discernable effects on viral replication or on symptoms caused by TLCV. Recently, certain monopartite begomoviruses including Ageratum yellow vein virus (AYVV), Cotton leaf curl virus (CLCuV), some begomoviruses infecting tomato and tobacco in China, and Bhendi yellow vein mosaic virus in India have been found to require DNA $\beta$ satellites for induction of disease symptoms in some host plants (Briddon et al. 2001; Jose and Usha 2003; Saunders et al. 2000; Zhou et al. 2003). These DNA $\beta$ satellites are about $1,350 \mathrm{nt}$ long and have some sequence similarity to TLCV satDNA and carry potential open reading frames (ORF). Like TLCV sat-DNA, DNA $\beta$ satellites require a helper virus for replication and encapsidation (Mansoor et al. 2003b; Stanley 2004). Despite their recent discovery, DNA $\beta$ satellites may have existed for many centuries. The DNA $\beta$ satellite associated with Eupatorium yellow-vein virus has been linked to disease symptoms described about 1,250 years ago (Saunders et al. 2003). The TLCV satellite DNA that lacks any ORF has been suggested as the remnant of a DNA $\beta$ that was at one time associated with this monopartite begomovirus (Saunders et al. 2000).

Cotton leaf curl disease (CLCuD) is a major constraint to the production of cotton in Pakistan. The disease has been reported to be caused by a combination of a DNA $\beta$ and either Cotton leaf curl Alabad virus, Cotton leaf curl Multan virus, Cotton leaf curl Khokhran virus, or Papaya leaf curl virus (Briddon 2003; Mansoor et al. 2003a; Zhou et al. 1998).

Analysis of DNA $\beta$ sequences has revealed a conserved organization consisting of a single complementary-sense ORF $(\beta C 1)$, an adenine-rich region, and a satellite-conserved region that carries sequence similarity to the TLCV sat-DNA (Briddon et al. 2003). Sequence analysis based on codon usage predicts another virion-sense ORF $(\beta \mathrm{V} 1)$ in DNA $\beta$ associated with CLCuV and AYVV (Briddon et al. 2001; Saunders et al. 2000). Here, we report that the $\beta C 1$ ORF is the pathogenicity determinant of DNA $\beta$ and causes disease-like symptoms when expressed in transgenic plants. A single polyadenlated 
transcript encoding this ORF was identified and mapped on the $\mathrm{CLCuV}$ DNA $\beta$ satellite $(\mathrm{CLCuV} \beta)$.

\section{RESULTS}

\section{TLCV can transreplicate CLCuV $\beta$.}

Inoculation of tobacco plants with a TLCV infectious clone produced mild mosaic (Fig. 1B) 18 to 21 days postinoculation (dpi), while inoculation with $\mathrm{CLCuV}$ did not produce any symptoms. Co-agroinoculation of tobacco with $\mathrm{CLCuV} \beta$ and either TLCV or CLCuV caused more severe symptoms indistinguishable from each other. The symptoms were downward curling of leaf margins, swelling and darkening of the veins, and the formation of small enations on the veins (Fig. 1C). Dot blot analysis of DNA extracted from the inoculated plants revealed that $\mathrm{CLCuV}$ replicated in tobacco but did not produce symptoms. Furthermore CLCuV $\beta$ could replicate in tobacco in the presence of either CLCuV or TLCV (data not shown). The frequency of coinfection of $\mathrm{CLCuV} \beta$ with $\mathrm{CLCuV}$ in tobacco plants was low (3/30) compared with that of coinfection with TLCV (10/10). Therefore, in subsequent experiments, TLCV was used as the helper virus.

\section{Disruption of the $\beta C 1$ ORF eliminates \\ the CLCuV $\beta$-associated phenotype.}

Tobacco plants $(n=9)$ coagroinoculated with TLCV and either $\mathrm{pBin}-\beta \mathrm{C} 1 \mathrm{Mut} 1$ or $\mathrm{pBin}-\beta \mathrm{C} 1 \mathrm{Mut} 2$ (Fig. $2 \mathrm{~B}$ ) developed typical TLCV symptoms 18 to $21 \mathrm{dpi}$ (Fig. 1D). The same number of plants coagroinoculated with TLCV and wild-type $\mathrm{CLCuV} \beta$ showed the more severe symptoms characteristic of
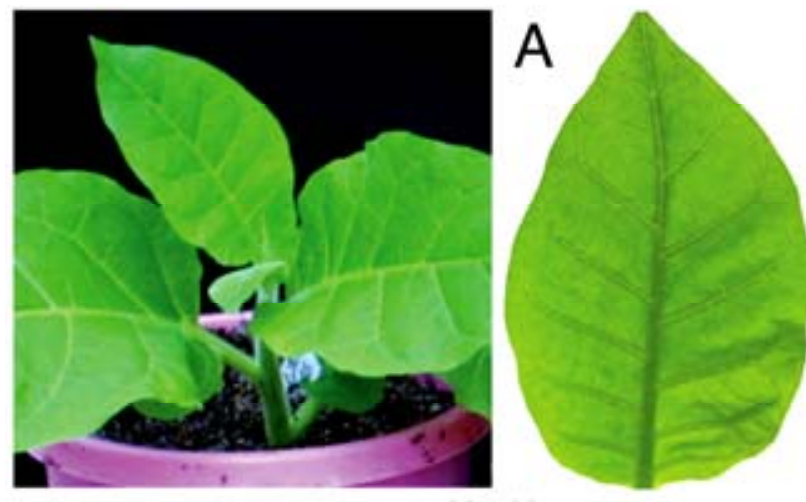

Healthy
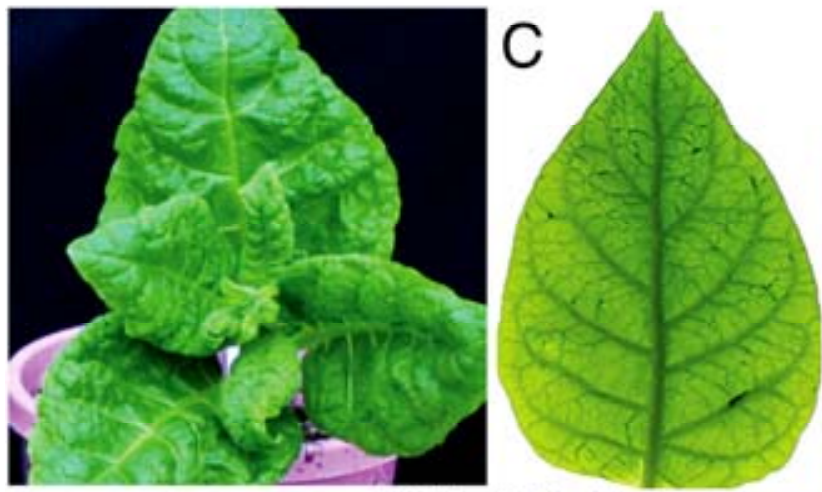

TLCV + CLCUVB
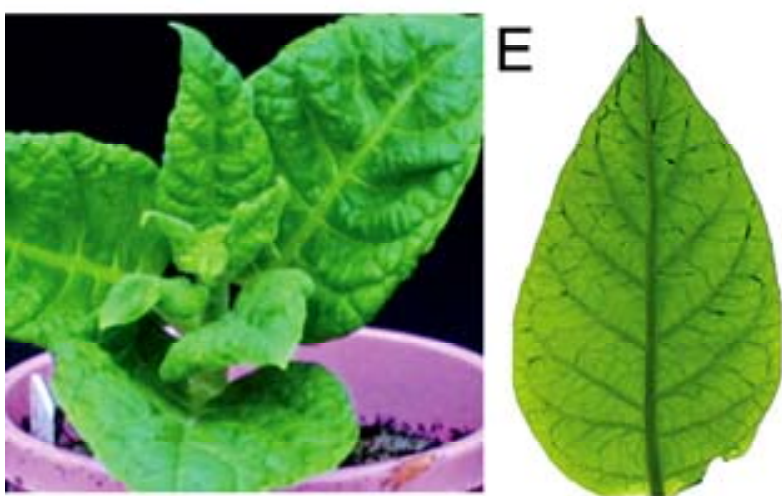
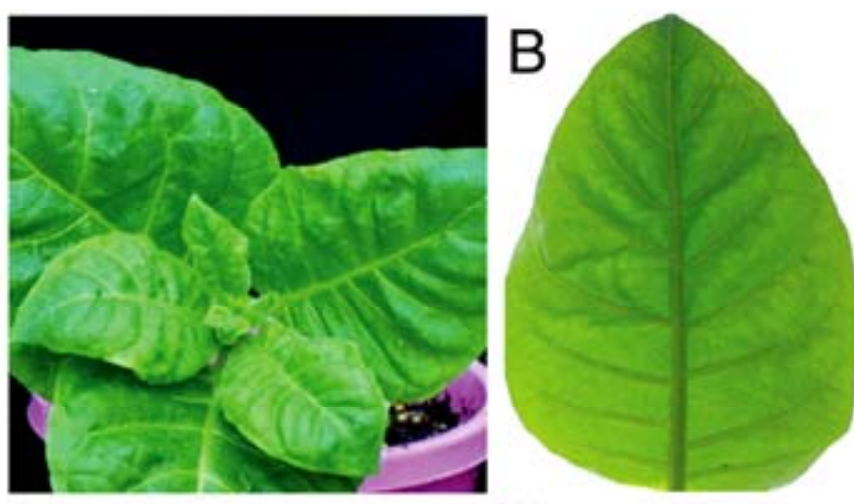

TLCV
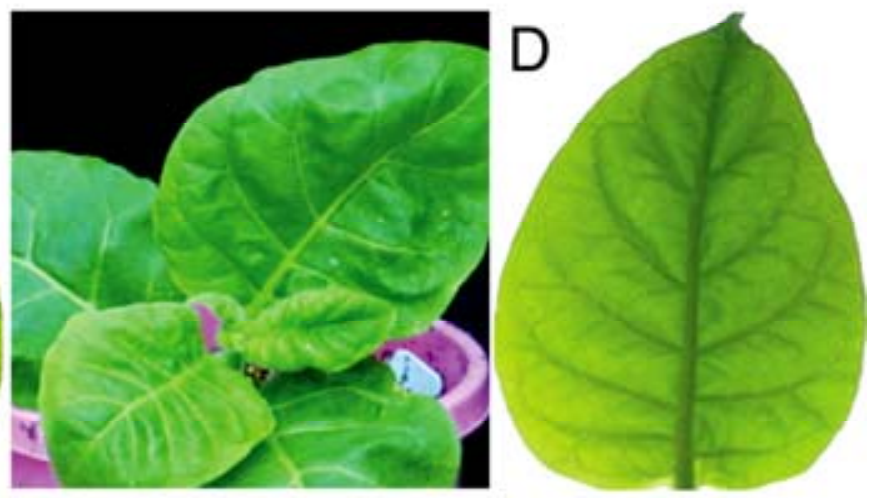

TLCV + BC1Mut

TLCV + BV1Mut

Fig. 1. Disruption of the $\beta C 1$ open reading frame eliminates the DNA $\beta$-associated phenotype. A, Uninfected tobacco plant. B, Mild mosaic in tobacco plants agroinoculated with Tomato leaf curl virus (TLCV) compared with $\mathbf{C}$, characteristic symptoms in plants co-agroinoculated with TLCV and Cotton leaf curl virus $(\mathrm{CLCuV}) \beta$. D, TLCV plus $\beta \mathrm{C} 1$ mutant compared with $\mathbf{E}$, characteristic symptoms in plants co-agroinoculated with TLCV and $\beta \mathrm{V} 1$ mutant. The leaves photographed with transmitted light are shown to highlight CLCuV $\beta$-associated vein-swelling phenotype. Pictures taken at 28 days postinoculation. 
CLCuV $\beta$ coinfection (Fig. 1C). These symptoms were indistinguishable from those plants coinoculated with TLCV and pBin- $\beta$ V1Mut (Figs. $1 \mathrm{E}$ and $2 \mathrm{~B}$ ), indicating that the $\beta \mathrm{V} 1$ does not have a role in symptom severity. Dot blot analysis of DNA extracted from inoculated plants showed the presence of DNA $\beta$ in all plants, irrespective of whether they were inoculated with wild-type or mutant DNA $\beta$ constructs. These results indicate that the $\beta C 1$ ORF is required for inducing severe disease symptoms in $N$. tabacum and that neither of the ORF encode a product essential for DNA $\beta$ replication.

\section{Expression of the $\beta \mathrm{C} 1$ gene}

\section{in transgenic plants results in growth abnormalities.}

Transgenic tobacco plants were generated to assess the effects of $\beta C 1$ expression under the control of either its own putative promoter or the Cauliflower mosaic virus (CaMV) $35 \mathrm{~S}$ promoter. During transformation, it was observed that some of the generated shoots were severely deformed and failed to develop into plantlets. Regeneration frequency from the $35 \mathrm{~S}-\beta \mathrm{C} 1$ construct (pART27- $\beta \mathrm{C} 1$ ) was extremely low, and only two transgenic lines could be recovered after a tenfold increase in the number of explants for transformation. One of the $35 \mathrm{~S}-\beta \mathrm{C} 1$ transgenic lines exhibited a severe phenotype. The plant was stunted and developed deformed leaves that were extremely small in size and had a rigid appearance (Fig. $3 \mathrm{~A})$. Another $35 \mathrm{~S}-\beta \mathrm{C} 1$ transgenic line showed less severe effects, grew to maturity, and produced seeds. In this transgenic line, some leaves showed vein swelling in small patches on the lower side of the leaves that was similar to the veinswelling symptom produced in tobacco and cotton plants coinfected with CLCuV and CLCuV $\beta$.

Tobacco plants were also transformed with a tandem repeat of DNA $\beta$. The pBin- $2 \beta$ construct was designed to derive $\beta C 1$ ORF expression by the putative promoter present in the DNA $\beta$ satellite. As the linear transgene contains an uninterrupted unit-length copy of DNA $\beta$, it is anticipated that expression from this linear template will be similar to that from the circular satellite DNA. The frequency of transformation with the pBin- $2 \beta$ construct was higher, and eight transgenic lines were recovered. The majority of these plants (six out of eight) showed a severe phenotype (Fig. 3B). They grew slowly and did not produce flowers, and their leaves were rigid and elongated. One of the transgenic lines showed a less severe phenotype, grew to maturity, and produced seeds. Several transgenic lines carrying the $35 \mathrm{~S}-\beta \mathrm{C} 1 \mathrm{Mut}$ (pART27- $\beta \mathrm{C} 1 \mathrm{Mut}$ ) construct were also produced, and all appeared normal (Fig. 3C). These results confirmed that the $\beta \mathrm{C} 1 \mathrm{ORF}$ product is responsible for the induction of a virus-like phenotype in the transgenic tobacco plants.

\section{Replicating DNA $\beta$ rescued from a dimeric $\beta$ transgenic plant following TLCV infection.}

Two independent $2 \beta$ transgenic tobacco lines were inoculated with TLCV. Southern blot analysis of DNA from the TLCV-infected $2 \beta$ transgenic tobacco plants 21 dpi revealed the presence of TLCV replicative DNA and DNA $\beta$ (Fig. 4A) of the same size as that present in nontransgenic tobacco plants coinoculated with TLCV and CLCuV $\beta$. No replicating form of DNA $\beta$ was observed in noninfected $2 \beta$ transgenic plants (Fig. 4A). These results indicate that replicating DNA $\beta$ was released from the transgenic plant chromosome and was amplified in the presence of TLCV.

After TLCV infection, the $2 \beta$ plants appeared to undergo a change of phenotype (Fig. 4B). At three weeks postinoculation, the transgene-associated phenotype began to diminish in severity, and within 10 weeks postinoculation, the symptoms of these plants were similar to the viral symptoms of nontrans- genic tobacco plants coinoculated with TLCV and CLCuV $\beta$. In contrast, there was no noticeable change of phenotype in the control noninfected $2 \beta$ plants. This observation indicates that the presence of replicating DNA $\beta$ in $2 \beta$ plants leads to a remission of the $\beta C 1$ phenotype.

TLCV-infected and noninfected plants of one of the two $2 \beta$ transgenic tobacco lines that produced seeds were selected for further studies. The seeds were germinated on MurashigeSkoog (MS) salts culture media containing kanamycin. It was observed that progeny plants from noninfected $2 \beta$ transgenic tobacco showed the parental transgene phenotype, whereas progeny from TLCV-infected $2 \beta$ plants produced the normal phenotype of nontransgenic healthy plants (Fig. 5). The progeny plants lacked TLCV infection, as the virus is not seedtransmitted (Seemanpillai et al. 2003). These results raised the possibility that $\beta C 1$ transgene expression was silenced by the replicating DNA $\beta$. A similar heritable silencing has been reported for TLCV-infected transgenic plants carrying a $\beta$ glucuronidase (GUS) ORF driven by the TLCV promoters (Seemanpillai et al. 2003).

\section{A single transcript encompasses the $\beta \mathrm{C1}$ ORF.}

Using a strand-specific probe for the full-length DNA $\beta$ molecule, Northern blot analysis of the $35 \mathrm{~S}-\beta \mathrm{C} 1$ line showing a severe phenotype and four 35S- $\beta$ C1Mut transgenic lines revealed the presence of two complementary-sense transcripts approximately 400 and $500 \mathrm{nt}$ in size. In contrast, a single transcript of approximately $400 \mathrm{nt}$ was detected in each of the two $2 \beta$ transgenic plants tested (Fig. 6). No transcript was detected with a virion-sense probe, even after prolonged expo-

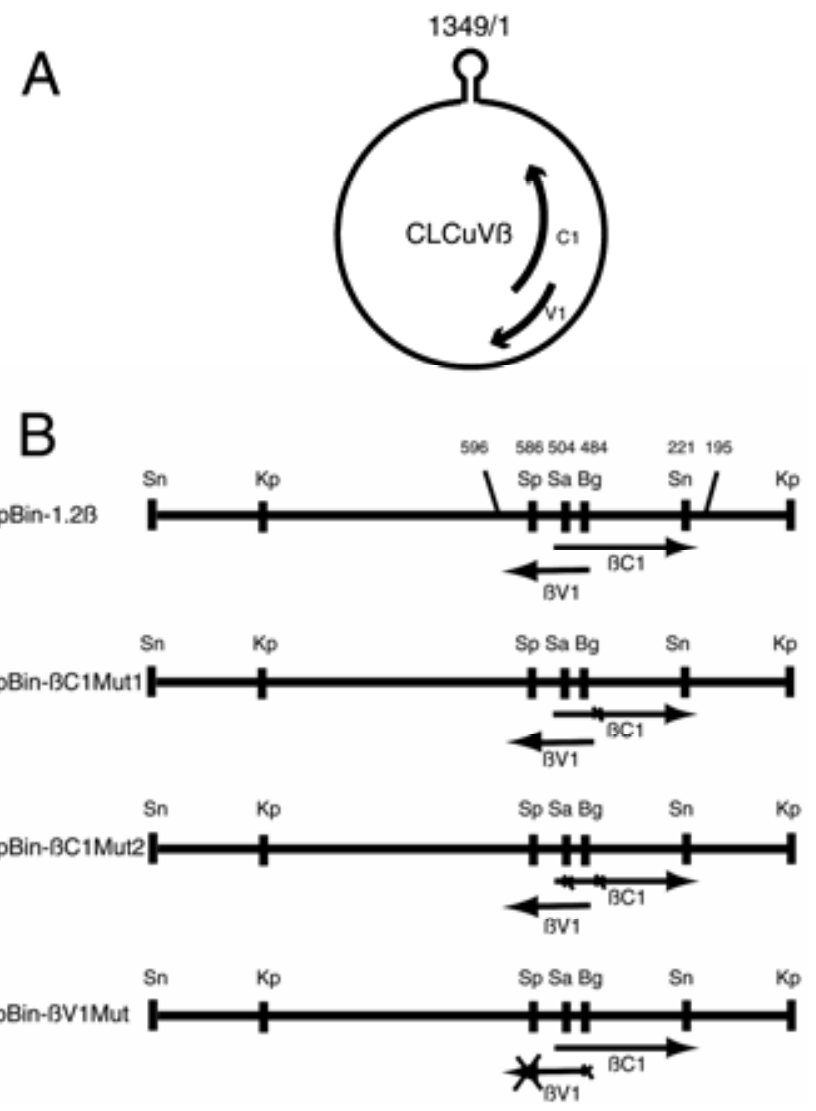

Fig. 2. A, Circular and B, linear maps of Cotton leaf curl virus $\beta$ and its mutant constructs. Open reading frames are shown by arrows and the positions of mutation are indicated by a cross (X). Restriction sites are: Sn, SnaBI; Kp, KpnI; Sp, SphI; Sa, SalI, and Bg, BglII. Numbering of residues is as in Briddon and associates (2001). 
sure of the blot to X-ray film (data not shown). There was a significant difference in the levels of $\beta \mathrm{C} 1 \mathrm{mRNA}$ accumulation in the transgenic plants containing the three constructs. The highest level of RNA accumulation was in plants expressing mutated $\beta \mathrm{C} 1$ under the control of $\mathrm{CaMV} 35 \mathrm{~S}$ promoter, followed by those containing the $2 \beta$ transgene and wild-type $\beta C 1$ driven by the CaMV 35S promoter (Fig.6). These results indicate that $\operatorname{CLCuV} \beta$ contains a transcription unit whose product has a similar size and function to the $\beta C 1$ transcript expressed by the CaMV $35 \mathrm{~S}$ promoter.

Amplification of the cDNA corresponding to the $5^{\prime}$ region of the $\beta C 1$ ORF by $5^{\prime}$-rapid amplification of cDNA ends (RACE) gave a DNA product of about $400 \mathrm{bp}$. Sequencing of seven independent clones of this cDNA revealed two clusters of $5^{\prime}$ ends at CLCuV $\beta$ coordinates 559 and 563 (Fig. 7). A promoter element, TATAAAT, was identified at nucleotides 588 to 594, $43 \mathrm{nt}$ upstream of the start codon. Amplification of cDNA corresponding to the $3^{\prime}$ region of the $\beta C 1$ ORF produced a DNA product of about $400 \mathrm{bp}$. Sequencing of five independent cDNA clones revealed $3^{\prime}$ ends at CLCuV $\beta$ coordinates 186 and 190 (Fig. 7). A polyadenylation signal, AATAAA, was found within the $\beta C 1$ coding region at nucleotides 209 to $214,18 \mathrm{nt}$ upstream of the stop codon. The position of the DNA $\beta$ - encoded transcript determined in this study and the potential regulatory elements are summarized in Figure 7 . We also attempted RACE polymerase chain reaction (PCR) using the $\beta V 1$-specific primers, but no consistent DNA products were amplified. These results indicate that $C L C u V \beta$ encodes a functional transcript that contains the $\beta \mathrm{C} 1 \mathrm{ORF}$.

\section{DISCUSSION}

The DNA $\beta$ satellite associated with CLCuD is supported for replication by four distinct cotton-infecting monopartite begomoviruses (Mansoor et al. 2003a). In this study, we show that $\mathrm{CLCuV} \beta$ can also use TLCV as a helper virus. Like the TLCV sat-DNA, the DNA $\beta$ satellite appears to be capable of using the replication-associated proteins (Rep) from a diverse range of begomoviruses (Dry et al. 1997). Given the high specificity of the geminiviral origin of DNA replication for cognate Rep (Fontes et al. 1994), it remains unclear how the geminivirus DNA satellite can achieve such promiscuity.

Comparison of 28 DNA $\beta$ species has shown that the position and size of the $\beta C 1$ ORF is conserved (Briddon et al. 2003). Furthermore, a potential virion-sense ORF $(\beta V 1)$ encoded by CLCuV and AYVV DNA $\beta$ has been predicted (Briddon et al.

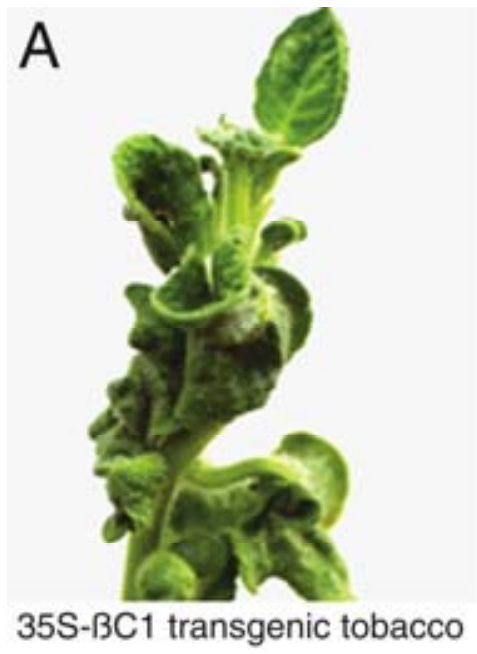

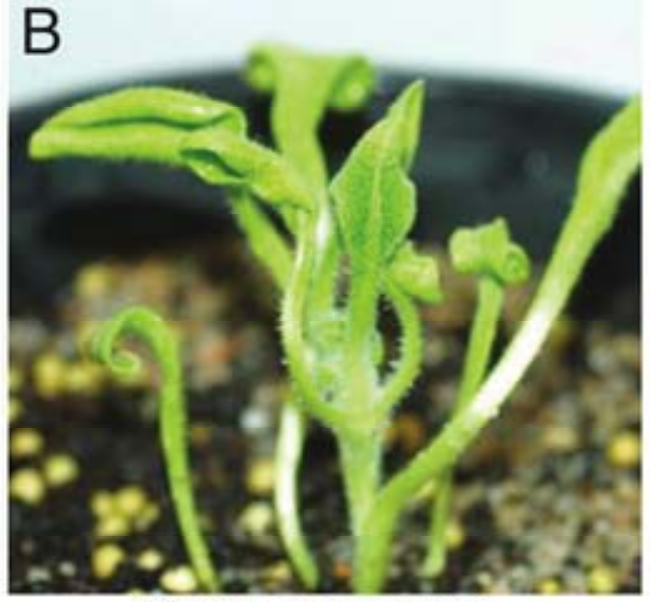

$2 ß$ transgenic tobacco

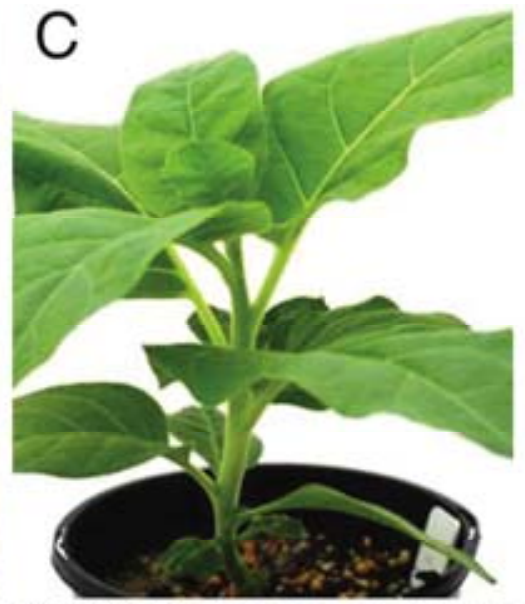

35S-BC1Mut transgenic tobacco

Fig. 3. Transgenic tobacco plants containing $35 \mathrm{~S}-\beta \mathrm{C} 1$ and $2 \beta$ displayed growth abnormalities. Plants shown are $\mathbf{A}, 35 \mathrm{~S}-\beta \mathrm{C} 1 \mathbf{B}, 2 \beta$, and $\mathbf{C}$, 35S- $\beta \mathrm{C} 1 \mathrm{Mut}$.

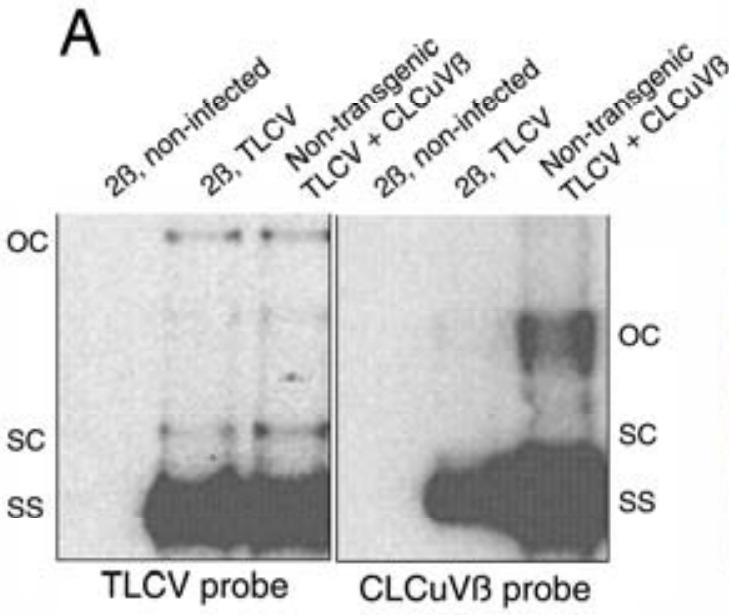

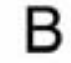

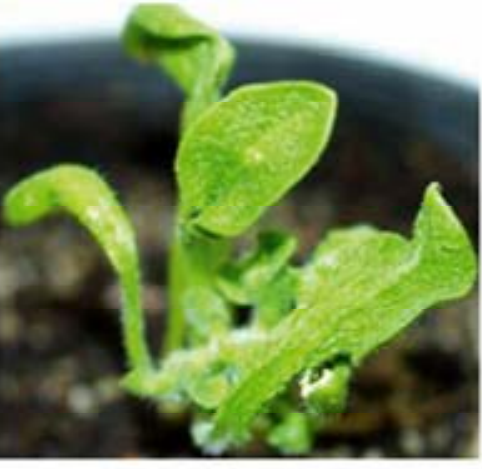

Non-infected $2 B$ transgenic

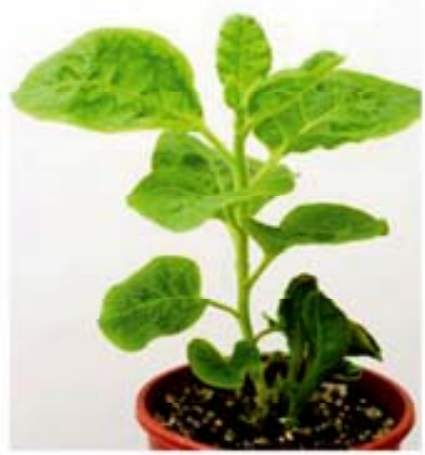

TLCV-infected $2 ß$ transgenic

Fig. 4. Replicating DNA $\beta$ rescued from a dimeric $\beta$ transgenic plant following Tomato leaf curl virus (TLCV) infection. A, Southern blot analysis showing replicating TLCV and Cotton leaf curl virus $(\mathrm{CLCuV}) \beta$ in the transgenic plants infected with TLCV. A DNA sample from a $2 \beta$ transgenic line is shown that is representative of the two $2 \beta$ transgenic lines analyzed. The blots were hybridized with either the TLCV or CLCuV $\beta$ probe. The position of single-stranded (SS), super coiled (SC), and open-circular (OC) DNA forms are indicated. B, A noninfected transgenic plant shows severe phenotype compared with milder symptoms in a TLCV-infected transgenic plant. Pictures taken at 55 days postinoculation. 
2001; Saunders et al. 2000). Therefore, we attempted to analyze the possible role of both ORF.

In this study, we used tobacco as the host plant for mutagenesis studies. Cotton, the natural host of $\mathrm{CLCuV} \beta$ was symptomless when inoculated with $\mathrm{CLCuV}$ alone but showed drastic symptoms when coinoculated with $\operatorname{CLCuV} \beta$ (Briddon et al. 2001; data not shown). However, inoculation efficiency of $\mathrm{CLCuV}$ in cotton was extremely low and rendered it impractical for our study. Nicotiana benthamiana was also tested but showed a severe symptom when inoculated with CLCuV with or without CLCuV $\beta$.

Evidence for the involvement of the $\beta C 1$ ORF in modulation of symptom expression has been provided before. Zhou and associates (2003) characterized a few DNA $\beta$ species associated with tomato- and tobacco-infecting begomoviruses and found that in-frame mutation of the $\beta \mathrm{C} 1$ initiation codon resulted in loss of symptom severity in $N$. benthamiana. They raised the possibility that mild symptoms could be attributed to leaky expression of the $\beta C 1$ gene from an in-frame start codon. Recently, Saunders and associates (2004) have demonstrated that disruption of the $\beta \mathrm{C} 1 \mathrm{ORF}$ prevented infection of the AYVV-satellite complex in ageratum and altered their phenotype in $N$. benthamiana to that produced by AYVV alone. We tested the infectivity of two $\beta \mathrm{C} 1$ mutant constructs, one with a stop codon at amino acid position 41 and another carrying two stop codons at positions 9 and 41, and found that both resulted in loss of pathogenicity in tobacco plants when coinoculated with TLCV. These results indicate that the $\beta C 1$ ORF is involved in pathogenicity and that the expression of its $\mathrm{N}$ terminal 40 amino acids is not sufficient for its function. In contrast to the $\beta \mathrm{C} 1 \mathrm{ORF}, \mathrm{CLCuV} \beta$ carrying a mutation in the putative $\beta$ V1 ORF produced a disease-like phenotype in tobacco plants indistinguishable from the wild-type CLCuV $\beta$ when coinoculated with TLCV. Therefore the $\beta$ V1 ORF has no apparent role in determining symptom severity in tobacco.
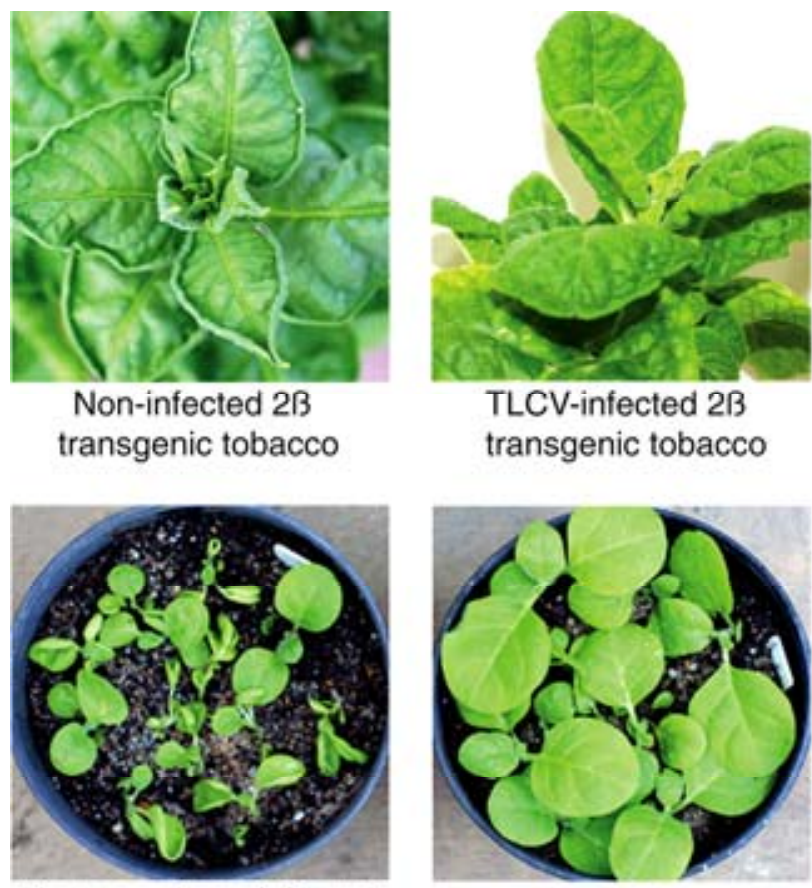

Progeny of non-infected transgenic tobacco

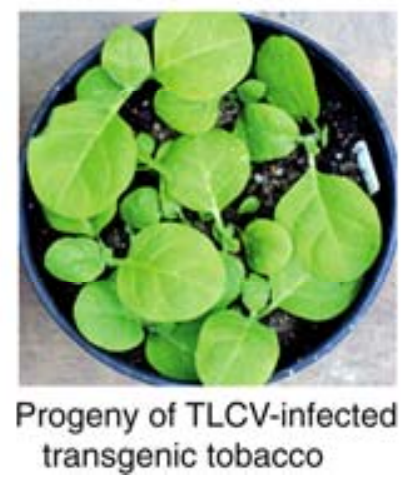

Fig. 5. Phenotypic remission of Tomato leaf curl virus (TLCV)-infected $2 \beta$ transgenic plants was heritable. Progeny of a noninfected $2 \beta$ transgenic plant showed inheritance of abnormal phenotype, whereas the progeny of a TLCV-infected $2 \beta$ transgenic plant showed a normal phenotype.
Our observation of virus-like phenotypes in tobacco plants expressing $\beta \mathrm{C} 1$, either under the control of the CaMV $35 \mathrm{~S}$ promoter or from a $\mathrm{CLCuV} \beta$ promoter, was consistent with the results of $\beta C 1$ mutagenesis. In contrast, the transgenic plants generated from mutant $\beta \mathrm{C} 1$ were indistinguishable from nontransgenic plants. These results confirm that $\beta \mathrm{C} 1$ is responsible for pathological symptoms associated with DNA $\beta$ infections. In a similar study, Saunders and associates (2004) transformed $N$. benthamiana plants with a dimeric AYVV $\beta$ and observed severe developmental abnormalities, vein-greening, and cell proliferation in the vascular bundles. The strong phenotype exhibited by $\beta C 1$ protein expression therefore appears to be a common feature of DNA $\beta$ satellites.

The virus-like phenotype developed by $\beta C 1$ transgenic plants were more severe than viral symptoms produced in nontransgenic tobacco plants coinfected with TLCV and $\mathrm{CLCuV} \beta$. A possible explanation for this is that the $\beta \mathrm{C} 1$ transgene is expressed in all tissues, whereas its expression is limited to phloem cells during the normal TLCV infection, in which the virus is localized (M. S. Rasheed and M. A. Rezaian, unpublished data). Another explanation is that the $\beta C 1$ may be down-regulated by viral-encoded proteins during normal infection (Hanley-Bowdoin et al. 1999), hence not resulting in the drastic effects observed in transgenic plants. As yet no experimental evidence for the possible regulation of $\beta \mathrm{C} 1$ is available.

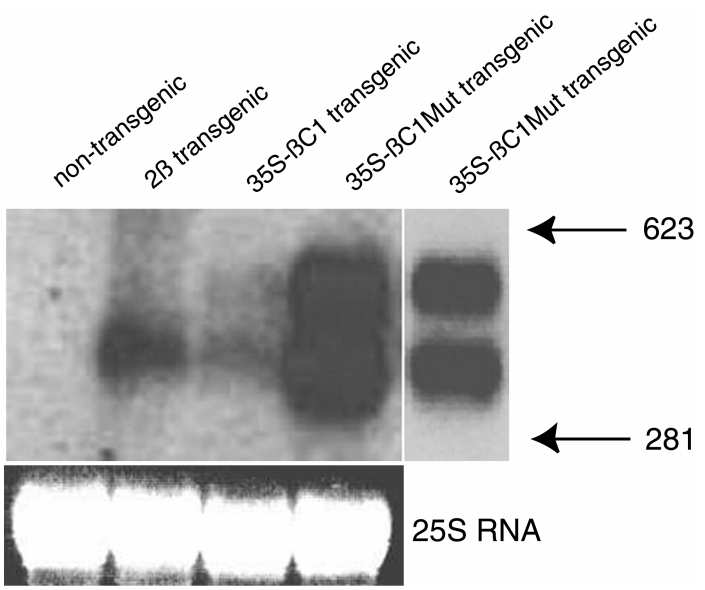

Fig. 6. Northern blot analysis of Cotton leaf curl virus (CLCuV) $\beta$ transcripts in plants transformed with either a dimeric $\beta$ construct ( $2 \beta$ transgene), $\beta \mathrm{C} 1$ (35S- $\beta \mathrm{C} 1$ transgene), or $\beta \mathrm{C} 1$ mutant (35S- $\beta \mathrm{C} 1$ Mut transgene). The $25 \mathrm{~S}$ rRNA band following ethidium bromide staining indicates the relative quantities of RNA analyzed. The positions of RNA markers are indicated. A shorter exposure for an RNA sample from the $35 \mathrm{~S}-\beta \mathrm{C} 1 \mathrm{Mut}$ transgenic plant is shown to clearly illustrate the presence of two transcripts.

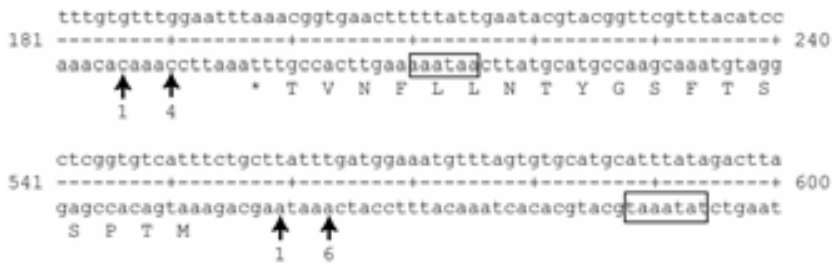

Fig. 7. Mapping of $3^{\prime}$ and $5^{\prime}$ ends of the $\beta C 1$ transcript. The nucleotide sequence of Cotton leaf curl virus $(\mathrm{CLCuV}) \beta$ between coordinates 181 to 240 and 541 to 600 and the $\beta C 1$ amino acid sequence in these regions are shown. The beginning of the $\beta \mathrm{C} 1$ open reading frame is indicated by the start codon for methionine $(\mathrm{M})$ and the end by a star $(*)$. The putative promoter TATA element and polyadenylation signal are boxed. The position and number of independent rapid amplification of cDNA end clones mapping to the $3^{\prime}$ and $5^{\prime}$ termini are indicated by arrows $(\mathbf{4})$. 
Seemanpillai and associates (2003) reported transcriptional silencing of geminiviral promoter-driven transgenes following homologous virus infection. Consistent with these results, the severe virus-like phenotype exhibited by $2 \beta$ transgenic tobacco plants were reduced, following inoculation with TLCV, to typical symptoms produced by coinoculation of TLCV and $\mathrm{CLCuV} \beta$ in nontransgenic tobacco plants. While we have not studied the fate of the $\beta C 1$ transcript, the silencing effect and its heritability closely resembles the TLCV-induced silencing of GUS transgenes driven by the viral promoters that involve transgene methylation (Seemanpillai et al. 2003).

Geminiviral genes conferring disease-like phenotypes on transgenic plants have been reported before. The BC1 (BL1) ORF of a number of bipartite begomoviruses have been implicated in symptom development, and their expression in their respective hosts produced phenotypes mimicking viral disease symptoms (Duan et al. 1997; Hou et al. 2000; Pascal et al. 1993). The C4 ORF of monopartite begomoviruses, including Beet curly top virus (Stanley and Latham 1992) and TLCV (Rigden et al. 1994), has been implicated as a determinant of symptom severity. Expression of $\mathrm{C} 4$ protein of these viruses under the control of CaMV 35S promoter produced virus-like symptoms in transgenic plants (Krake et al. 1998; Latham et al. 1997). $\beta C 1$ is another geminivirus-encoded gene that confers a virus-like phenotype on transgenic plants. The exact roles of these proteins in geminiviral pathogenesis remain unknown.

Northern blot analysis of transgenic lines expressing wildtype and mutant $\beta \mathrm{C} 1$ revealed the existence of two $\beta \mathrm{C} 1$ mRNA transcripts approximately 400 and $500 \mathrm{nt}$ in size. No virion-sense transcript of $\mathrm{CLCuV} \beta$ was detected. The lack of virion-sense transcript is consistent with our finding that the virion sense ORF ( $\beta \mathrm{V} 1)$ is not involved in either DNA $\beta$ replication or in symptom expression. A single transcript was found in the dimeric DNA $\beta$ transgenic plants analyzed. In addition to a transcript of similar size, a longer transcript was also found in plants expressing either wild-type $\beta \mathrm{C} 1$ or mutant $\beta \mathrm{C} 1$ under the control of the CaMV $35 \mathrm{~S}$ promoter. A possible reason for this is the presence of two polyadenylation signals in the $35 \mathrm{~S}-\beta \mathrm{C} 1$ construct, one in the $\beta \mathrm{C} 1$ (Fig. 7), and another in the termination sequence of the expression cassette.

We observed significant differences in the levels of $\beta \mathrm{C} 1$ mRNA accumulation among the plants transformed with wildtype and mutant $\beta \mathrm{C} 1$. The level of expression in mutated $\beta \mathrm{C} 1$ transgenic plants was several-fold higher compared with the wild-type $\beta C 1$ transgenic plants (Fig. 6). In studies with Squash leaf curl virus BC1/BL1-expressing transgenic plants (Pascal et al. 1993) and with TLCV C4-expressing transgenic plants (Krake et al. 1998), comparable levels of accumulation of wild-type and mutant ORF expressed from the CaMV 35S promoter were observed. It is possible that constitutive expression of $\beta \mathrm{C} 1$ from the $\mathrm{CaMV} 35 \mathrm{~S}$ promoter is lethal to tobacco plants. This is consistent with the extremely low frequency of regeneration of $35 \mathrm{~S}-\beta \mathrm{C} 1$ transgenic plants observed here. In this regard, $\beta C 1$ resembles the Rep genes (C1) of TLCV (Dry et al. 2000) or a closely related Begomovirus, Tomato yellow leaf curl virus (Bendahmane and Gronenborn 1997), whose expression in transgenic plants has not been attained, possibly because Rep induces a hypersensitive response (Selth et al. 2004).

The DNA encoding the $\beta \mathrm{C} 1$ transcript identified has a promoter TATA element (Breathnach and Chambon 1981) $43 \mathrm{nt}$ upstream of the putative start codon. The presence of two distinct $5^{\prime}$ ends in close proximity to a putative promoter element has been observed previously in transcripts of plant and geminivirus genes (Baulcombe et al. 1987; Mullineaux et al. 1993). Mapping of the $3^{\prime}$ end also revealed two distinct $3^{\prime}$ ends. The $3^{\prime}$ region of the $\beta \mathrm{C} 1 \mathrm{mRNA}$ contained a consensus polyadenylation signal (Fig. 7) (Joshi 1987). In contrast to our results, the $3^{\prime}$ ends of transcripts encoded by AYVV $\beta$ mapped uncharacteristically to several different locations downstream of the putative termination codon (Saunders et al. 2004).

Our results suggest that $\mathrm{CLCuV} \beta$ encodes an $\mathrm{ORF}, \beta \mathrm{C} 1$, which modulates geminiviral symptom severity. The mechanism by which $\beta \mathrm{C} 1$ induces disease symptoms remains unknown and may include changes in virus spread, replication of helper virus, or specific interaction with host proteins. Using a yeast two-hybrid system, we have identified potential $\beta \mathrm{C} 1$-interacting host proteins that are currently being characterized.

\section{MATERIALS AND METHODS}

\section{Construction of clones.}

A full-length $K p n I$ monomeric DNA of the CLCuV $\beta$ was released from plasmid pCLC $\beta 02$ (Briddon et al. 2001) and ligated at the KpnI site of pBluescript II SK+ (Stratagene, La Jolla, CA, U.S.A.) in both virion- and complementary-sense orientations, to produce $\mathrm{pBS}-\beta$ to use as template for synthesis of strand-specific probes.

A 280-bp SnaBI/KpnI fragment of DNA $\beta$ was cloned into the binary transformation vector pBin20 (Hennegan and Danna 1998) to produce pBin-0.2 $\beta$. An infectious head-to-tail 1.2 mer of DNA $\beta$ was constructed by ligating the KpnI monomer into $\mathrm{pBin}-0.2 \beta$ to produce $\mathrm{pBin}-1.2 \beta$ that contains a single copy of $\beta \mathrm{C} 1$ and $\beta \mathrm{V} 1$ ORF (Fig. $2 \mathrm{~B}$ ). The identity of clones was confirmed by restriction analysis. Agroinfectious constructs of TLCV and CLCuV (Briddon et al. 2000; Dry et al. 1997) have been described previously.

\section{Mutagenesis of $\mathrm{C} 1$ and V1 ORF of CLCuV $\beta$.}

Site-directed mutagenesis of $\beta C 1$ was carried out by PCR, using two flanking oligonucleotide primers (P1-V and P3-C; Table 1), to amplify a 290-bp fragment (nucleotide 195 to nucleotide 484; Fig. 2B). The mutant fragment containing a premature stop codon at amino acid position 41 was digested with SnaBI and $B g l I I$, and the resulting 252-bp DNA was introduced into $\mathrm{pBS}-\beta$ clone, from which the corresponding wild-

Table 1. Cotton leaf curl virus (CLCuV) $\beta$-specific oligonucleotides primers

\begin{tabular}{lccl}
\hline Primers $^{\mathbf{a}}$ & Size (nt) & Nucleotide position $^{\mathbf{b}}$ & \multicolumn{1}{c}{ Sequence $\left(\mathbf{5}^{\prime} \text { to } \mathbf{3}^{\prime}\right)^{\mathbf{c}}$} \\
\hline P1-V & 24 & 195 to 209 & GGCAAGCTTTTAAACGGTGAACTT \\
P2-V & 24 & 472 to 486 & CGACTCGAGATGAAGATCTTCATA \\
P3-C & 60 & 425 to 484 & TGAAGATCTTCATTCACATGAGGATACTATCCACAAAGTCACCATCGCTAATCTAGTATG \\
P4-C & 23 & 459 to 484 & TGAAGATCTTTATTCACATGAGG \\
P5-V & 33 & 504 to 533 & AACGTCGACTATGAACCTGACTCCCTACTTGTT \\
P6-C & 24 & 536 to 551 & TAACTCGAGATGACACCGAGCGGA \\
P7-C & 25 & 573 to 596 & TCTATAAATGCATGCACACTAAAC \\
P8-C & 24 & 606 to 621 & ACCTCTAGACTA CACAAAATATCT \\
\hline
\end{tabular}

${ }^{\mathrm{a}} \mathrm{V}=$ virion-sense; $\mathrm{C}=$ complementary sense.

${ }^{\mathrm{b}}$ Nucleotide position of CLCuV $\beta$ as in Briddon and associates (2001).

${ }^{\mathrm{c}}$ Bold characters show mutations; restriction sites are underlined. 
type fragment had been removed, to produce pBS- $\beta$ C1Mut1. Another stop codon was introduced at codon position 9 by amplifying a 93-bp fragment (nucleotides 504 to 596; Fig. 2B) using the flanking oligonucleotides P5-V and P7-C (Table 1). This fragment was digested with SalI and SphI and was used in PCR as a mutant mega primer along with the P1 primer (Table 1) to amplify the 391-bp SnaBI/SphI fragment from pBS$\beta C 1 M u t 1$ (Fig. 2B). The amplified DNA containing two introduced stop codons was digested with $S n a \mathrm{BI}$ and $S p h \mathrm{I}$ and was introduced into pBS- $\beta$ from which the corresponding wildtype fragment had been removed to produce $\mathrm{pBS}-\beta \mathrm{C} 1 \mathrm{Mut} 2$ (Fig. 2B).

A $\beta V 1$ frame-shift mutant at nucleotide position 586 was produced by digesting the pBS- $\beta$ with SphI, removing the $3^{\prime}$ overhang by treatment with T4 DNA polymerase followed by blunt end religation to produce $\mathrm{pBS}-\beta \mathrm{V} 1 \mathrm{FS}$. In addition, the ATG initiation codon of the V1 ORF was changed to ATA by PCR, using two flanking oligonucleotide primers (P1-V and P4-C; Table 1) to amplify a 290-bp DNA (nucleotides 195 to 484; Fig. 2B). This fragment was digested with SnaBI and $B g l I I$, and the resulting 252-bp DNA was introduced into pBS$\beta \mathrm{V} 1 \mathrm{FS}$ from which the corresponding wild-type sequence had been removed, to produce pBS- $\beta$ V1Mut (Fig. 2B). All constructs were sequenced to verify the mutations introduced. All mutant constructs that were initially produced as monomer clones were released and ligated into $\mathrm{pBin}-0.2 \beta$ and were introduced into Agrobacterium tumefaciens C58.

\section{Whole-plant infectivity assays.}

A. tumefaciens cultures harboring a tandem-repeat construct of either TLCV in pBin 19 or CLCuV $\beta$ in pBin20 were grown for 36 to $48 \mathrm{~h}$, were mixed in equal proportions, and were inoculated into the axillary buds of $N$. tabacum plants, as described previously (Rigden et al. 1996). Developing leaves were sampled 21 to 28 days after inoculation. The presence of viral DNAs was detected by dot blot analysis, using the fulllength ${ }^{32} \mathrm{P}$-labeled TLCV or $\mathrm{CLCuV} \beta$ probes as described (Behjatnia et al. 1996).

\section{Plant transformation.}

The entire $\beta \mathrm{C} 1 \mathrm{ORF}$ was amplified from clone $\mathrm{pBS}-\beta$ with oligonucleotides P1-V and P6-C (Table 1). The 363-bp PCR product was digested with $X h o \mathrm{I}$ and HindIII and was cloned into the plant expression vector pART7 (Gleave 1992) to produce pART7- $\beta C 1$. The expression cassette containing the CaMV 35S promoter, the $\beta C 1 \mathrm{ORF}$, and the octopine synthase gene $3^{\prime}$ untranslated region was released by digestion with NotI and was ligated into the binary transformation vector pART27 (Gleave 1992) to produce pART27- $\beta C 1$. pART27$\beta C 1$ Mut, containing a mutant $\beta C 1$, was produced similarly, using clone pBS- $\beta \mathrm{C} 1 \mathrm{Mut} 2$ as the DNA template in PCR. The integrity of the $\beta \mathrm{C} 1$ and $\beta \mathrm{C} 1 \mathrm{Mut} \mathrm{ORF}$ were confirmed by sequencing.

A head-to-tail dimeric clone of $\mathrm{CLCuV} \beta$ was obtained directly, using a 10:1 molar ratio of insert to vector (pBS SK+) in the ligation reaction, to produce $\mathrm{pBS}-2 \beta$. This construct was cloned into the HindIII site of the binary vector pBin19 to produce $\mathrm{pBin}-2 \beta$.

The pART27- $\beta \mathrm{C} 1$, pART27- $\beta \mathrm{C} 1 \mathrm{Mut}$, and $\mathrm{pBin}-2 \beta$ constructs were introduced into $A$. tumefaciens LBA4404 by electroporation. Tobacco (N. tabacum cv. Samsun) was transformed with the constructs as described (Horsch et al. 1985). Transgenic shoots $(2 \beta, 35 \mathrm{~S}-\beta \mathrm{C} 1$, and $35 \mathrm{~S}-\beta \mathrm{C} 1 \mathrm{Mut})$ were selected on $0.7 \%$ bacto-agar plates containing culture medium $(0.43 \% \mathrm{MS}$ salts, $3 \%$ sucrose, $0.01 \%$ Gamborg vitamins) supplemented with $250 \mu \mathrm{g}$ of kanamycin per milliliter and grown at 25 to $27^{\circ} \mathrm{C}$ under artificial light $\left(150 \mu \mathrm{E} \mathrm{s}^{-1} \mathrm{~m}^{-2}\right)$ with a 16 -h photo- period. Transgenic plants were transferred to potting soil and were maintained in the glasshouse under natural light at 25 to $30^{\circ} \mathrm{C}$.

\section{Northern blot analysis of RNA from transgenic plants.}

RNA was isolated from $2 \beta, 35 \mathrm{~S}-\beta \mathrm{C} 1$, and $35 \mathrm{~S}-\beta \mathrm{C} 1 \mathrm{Mut}$ transgenic lines using plant RNA reagent (Invitrogen, Carlsbad, CA, U.S.A.). Samples of RNA $(20 \mu \mathrm{g})$ were electrophoresed in a $1.5 \%$ formaldehyde agarose gel and were blotted onto nylon membrane (BioRad, Hercules, CA, U.S.A.). Blotted RNA was hybridized overnight at $68^{\circ} \mathrm{C}$ (Sambrook and Russell 2001) with strand-specific ${ }^{32} \mathrm{P}$ UTP-labeled full-length DNA $\beta$ probes, produced using a T7 RNA polymerase kit (Promega, Madison, WI, U.S.A.) and the full-length CLCuV $\beta$ DNA template in $\mathrm{pBS}$ $(\mathrm{pBS}-\beta)$.

\section{Mapping the termini of $\mathrm{CLCuV} \beta$ transcript.}

The $3^{\prime}$ end of CLCuV $\beta$-encoded RNA was mapped using the 3' RACE procedure (Frohman et al. 1988). Poly $\mathrm{A}^{+}$template RNA was prepared from a $2 \beta$ transgenic line using mRNA isolation systems (Promega). First-strand cDNA was synthesized using an oligo-dT primer. The cDNA was used as a template in PCR, with oligo-dT primer and a gene-specific primer (P2-V or P6-C) (Table 1) to amplify either $\beta \mathrm{C} 1$ or $\beta \mathrm{V} 1$ putative transcripts, using a one step reverse transcriptase-PCR system (Invitrogen). The product was cloned into the pGem-T Easy vector (Promega) and was sequenced. Similarly, the 5' end of CLCuV $\beta$-encoded RNA was mapped, using the 5'RACE procedure (Frohman et al. 1988). First-strand cDNA was synthesized by reverse transcriptase using oligo-dT primer (Invitrogen) and was tailed with $\mathrm{dC}$, using terminal transferase. An oligo-dG primer and the gene-specific primer for either the $\beta \mathrm{C} 1$ or $\beta \mathrm{V} 1$ ORF (P1-V or P8-C) (Table 1) were used to amplify the cDNA. The DNA product was cloned into pGem-T Easy vector (Promega) and sequenced.

\section{ACKNOWLEDGMENTS}

We thank K. Malik for his support of the project and R. Briddon for providing the infectious clones of $\mathrm{CLCuV}$ and $\mathrm{CLCuV} \beta$. M. Saeed is a visiting Ph.D. student from NIBGE funded by the Australian Center for International Agricultural Research (ACIAR).

\section{LITERATURE CITED}

Baulcombe, D. C., Barker, R. F., and Jarvis, M. G. 1987. A gibberellin responsive wheat gene has homology to yeast carboxypeptidase Y. J. Biol. Chem. 262:13726-13735.

Behjatnia, S. A. A., Dry, I. B., Krake, L. R., Condé, B. D., Connelly, M. I., Randles, J. W., and Rezaian, M. A. 1996. New potato spindle tuber viroid and tomato leaf curl geminivirus strains from a wild Solanum sp. Phytopatholology 86:880-886.

Bendahmane, M., and Gronenborn, B. 1997. Engineering resistance against tomato yellow leaf curl virus (TYLCV) using antisense RNA. Plant Mol. Biol. 33:351-357.

Breathnach, R., and Chambon, P. 1981. Organization and expression of eukaryotic split genes coding for proteins. Annu. Rev. Biochem. 50:349-383.

Briddon, R. W. 2003. Cotton leaf curl disease, a multicomponent begomovirus complex. Mol. Plant Pathol. 4:427-434.

Briddon, R. W., Bull, S. E., Amin, I., Idris, A. M., Mansoor, S., Bedford, I. D., Dhawan, P., Rishi, N., Siwatch, S. S., Abdel-Salam, A. M., Brown, J. K., Zafar, Y., and Markham, P. G. 2003. Diversity of DNA $\beta$, a satellite molecule associated with some monopartite begomoviruses. Virology 312:106-121.

Briddon, R. W., Mansoor, S., Bedford, I. D., Pinner, M. S., and Markham, P. G. 2000. Clones of cotton leaf curl geminivirus induce symptoms atypical of cotton leaf curl disease. Virus Genes 20:19-26.

Briddon, R. W., Mansoor, S., Bedford, I. D., Pinner, M. S., Saunders, K., Stanley, J., Zafar, Y., Malik, K. A., and Markham, P. G. 2001. Identification of DNA components required for induction of cotton leaf curl disease. Virology 285:234-243. 
Brown, J. K., and Bird, J. 1992. Whitefly-transmitted geminiviruses and associated disorders in the Americas and the Caribbean basin. Plant Dis. 76:220-225.

Dry, I. B., Krake, L. R., Mullineaux, P. M., and Rezaian, M. A. 2000. Regulation of tomato leaf curl viral gene expression in host tissues. Mol. Plant-Microbe Interact. 13:529-537.

Dry, I. B., Krake, L. R., Rigden, J. E., and Rezaian, M. A. 1997. A novel subviral agent associated with a geminivirus: The first report of a DNA satellite. Proc. Natl. Acad. Sci. U.S.A. 94:7088-7093.

Dry, I. B., Rigden, J. E., Krake, L. R., Mullineaux, P. M., and Rezaian, M. A. 1993. Nucleotide sequence and genome organization of tomato leaf curl geminivirus. J. Gen. Virol. 74:147-151.

Duan, Y.-P., Powell, C. A., Purcifull, D. E., Broglio, P., and Hiebert, E. 1997. Phenotypic variation in transgenic tobacco expressing mutated geminivirus movement/pathogenicity (BC1) proteins. Mol. PlantMicrobe Interact. 10:1065-1074.

Fontes, E. P. B., Gladfelter, H. J., Schaffer, R. L., Petty, I. T. D., and HanleyBowdoin, L. 1994. Geminivirus replication origins have a modular organization. Plant Cell 6:405-416.

Frohman, M. A., Dush, M. K., and Martin, G. R. 1988. Rapid production of full-length cDNAs from rare transcripts: Amplification using a single gene-specific oligonucleotide primer. Proc. Natl. Acad. Sci. U.S.A. 85:8998-9002.

Gleave, A. P. 1992. A versatile binary vector system with a T-DNA organisational structure conducive to efficient integration of cloned DNA into the plant genome. Plant Mol. Biol. 6:1203-1207.

Hanley-Bowdoin, L., Settlage, S. B., Orozco, B. M., Nagar, S., and Robertson, D. 1999. Geminiviruses: Models for plant DNA replication, transcription, and cell cycle regulation. Crit. Rev. Plant Sci. 18:71-106.

Hennegan, K. P., and Danna, K. J. 1998. pBIN20: An improved binary vector for Agrobacterium-mediated transformation. Plant Mol. Biol. Rep. 16:129-131.

Horsch, R. B., Fry, J. E., Hoffmann, N. L., Eichholtz, D., Rogers, S. G., and Fraley, R. T. 1985. A simple and general method for transferring genes into plants. Science 227:1229-1231.

Hou, Y.-M., Sanders, R., Ursin, V. M., and Gilbertson, R. L. 2000. Transgenic plants expressing geminivirus movement proteins: Abnormal phenotypes and delayed infection by Tomato mottle virus in transgenic tomatoes expressing the Bean dwarf mosaic virus $\mathrm{BV} 1$ or $\mathrm{BC} 1$ proteins. Mol. Plant-Microbe Interact. 13:297-308

Jose, J., and Usha, R. 2003. Bhendi yellow vein mosaic disease in India is caused by association of a DNA $\beta$ satellite with a begomovirus. Virology 305:310-317.

Joshi, C. P. 1987. Putative polyadenylation signals in nuclear genes of higher plants: A compilation and analysis. Nucleic Acids Res. 15:9627-9640.

Kheyr-Pour, A., Bendahmane, M., Matzeit, V., Accotto, G. P., Crespi, S., and Gronenborn, B. 1991. Tomato yellow leaf curl virus from Sardinia is a whitefly-transmitted monopartite geminivirus. Nucleic Acids Res. 19:6763-6769.

Klinkenberg, F. A., and Stanley, J. 1990. Encapsidation and spread of African cassava mosaic virus DNA A in the absence of DNA B when agroinoculated to Nicotiana benthamiana. J. Gen. Virol. 71:1409-1412.

Krake, L. R., Rezaian, M. A., and Dry, I. B. 1998. Expression of the tomato leaf curl geminivirus $C 4$ gene produces viruslike symptoms in transgenic plants. Mol. Plant-Microbe Interact. 11:413-417.

Latham, J. R., Saunders, K., Pinner, M. S., and Stanley, J. 1997. Induction of plant cell division by beet curly top virus gene $C 4$. Plant J. 11:12731283

Mansoor, S., Briddon, R. W., Bull, S. E., Bedford, I. D., Bashir, A., Hussain, M., Saeed, M., Zafar, Y., Malik, K. A., Fauquet, C. M., and Markham, P.
G. 2003a. Cotton leaf curl disease is associated with multiple monopartite begomoviruses supported by single DNA $\beta$. Arch. Virol. 148:1969-1986.

Mansoor, S., Briddon, R. W., Zafar, Y., and Stanley, J. 2003b. Geminivirus disease complexes: An emerging threat. Trends Plant Sci. 8:128-134.

Mullineaux, P. M., Rigden, J. E., Dry, I. B., Krake, L. R., and Rezaian, M. A. 1993. Mapping of the polycistronic RNAs of tomato leaf curl geminivirus. Virology 193:414-423.

Navot, N., Pichersky, E., Zeidan, M., Zamir, D., and Czosnek, H. 1991. Tomato yellow leaf curl virus: A whitefly-transmitted geminivirus with a single genomic component. Virology 185:151-161.

Noris, E., Hidalgo, E., Accotto, G. P., and Moriones, E. 1994. High similarity among the tomato yellow leaf curl virus isolates from the west Mediterranean basin: The nucleotide sequence of an infectious clone from Spain. Arch. Virol. 135:165-170.

Noueiry, A. O., Lucas, W. J., and Gilbertson, R. L. 1994. Two proteins of a plant DNA virus coordinate nuclear and plasmodesmal transport. Cell 76:925-932.

Pascal, E., Goodlove, P. E., Wu, L. C., and Lazarowitz, S. G. 1993. Transgenic tobacco plants expressing the geminivirus BL1 protein exhibit symptoms of viral disease. Plant Cell 5:795-807.

Rigden, J. E., Dry, I. B., Krake, L. R., and Rezaian, M. A. 1996. Plant virus DNA replication processes in Agrobacterium: Insight into the origins of geminiviruses? Proc. Natl. Acad. Sci. U.S.A. 93:10280-10284.

Rigden, J. E., Krake, L. R., Rezaian, M. A., and Dry, I. B. 1994. ORF C4 of tomato leaf curl geminivirus is a determinant of symptom severity. Virology 204:847-850.

Sambrook, J., and Russell, D. W. 2001. Molecular Cloning: A Laboratory Manual, 3rd ed. Cold Spring Harbor Laboratory Press, Cold Spring Harbor, NY, U.S.A.

Saunders, K., Norman, A., Gucciardo, S. and Stanley. J. 2004. The DNA $\beta$ satellite component associated with ageratum yellow vein disease encodes an essential pathogenicity protein ( $\beta C 1)$. Virology 324:37-47.

Saunders, K., Bedford, I. D., Briddon, R. W., Markham, P. G., Wong, S. M., and Stanley, J. 2000. A unique virus complex causes Ageratum yellow vein disease. Proc. Natl. Acad. Sci. U.S.A. 97:6890-6895.

Saunders, K., Bedford, I. D., Yahara, T., and Stanley, J. 2003. Aetiology: The earliest recorded plant virus disease. Nature 422:831.

Seemanpillai, M., Dry, I., Randles, J., and Rezaian, A. 2003. Transcriptional silencing of geminiviral promoter-driven transgenes following homologous virus infection. Mol Plant-Microbe Interact. 16:429-438.

Selth, L. A., Randles, J. W., and Rezaian, M. A. 2004. Host responses to transient expression of individual genes encoded by Tomato leaf curl virus. Mol. Plant- Microbe Interact. 17:27-33.

Stanley, J. 2004. Subviral DNAs associated with geminivirus disease complexes. Vet Microbiol. 98:121-129.

Stanley, J., and Gay, M. R. 1983. Nucleotide sequence of cassava latent virus DNA. Nature 301:2660-2662.

Stanley, J., and Latham, J. R. 1992. A symptom variant of beet curly top geminivirus produced by mutation of open reading frame $\mathrm{C} 4$. Virology 190:506-509.

von Arnim, A., and Stanley, J. 1992. Determinants of tomato golden mosaic virus symptom development located on DNA B. Virology 186:286-293.

Zhou, X., Liu, Y., Robinson, D. J., and Harrison, B. D. 1998. Four DNA-A variants among Pakistani isolates of cotton leaf curl virus and their affinities to DNA-A of geminivirus isolates from okra. J. Gen. Virol. 79:915-923.

Zhou, X., Xie, Y., Tao, X., Zhang, Z., Li, Z., and Fauquet, C. M. 2003. Characterization of DNA $\beta$ associated with begomoviruses in China and evidence for co-evolution with their cognate viral DNA-A. J. Gen. Virol. 84:237-247. 